\title{
CONTRIBUIÇÃO AO ESTUDO DOS TEORES SERICOS SANGỨNEOS DO CÁLCIO, FÓSFORO E MAGNÉSIO DURANTE A PRENHEZ DA JUMENTA, EQUUS ASINUS, LINNAEUS, 1758. (Perissadactyla, Equidae).
}

Maria Ely Miserochi de OLIVEIRA * José de F. TABARELLI NETO **

Oziel BIZUTTI *

\section{RFMV-A/16}

Oliveira, M. E. M.; Tabarelli Neto, J. F.; Bizutti, O. - Contribuiçāo ao estudo dos teores séricos sanguíneos do cálcio, fósforo e magnésio durante a prenhez da jumenta, Equus asinus, Linnaeus, 1758. (Perissodactyla, Equidae). Rev. Fac. Med. vet. Zootec. Univ. S. Paulo, 12:169-84, 1975.

RESUMo: Foram analisados os níveis séricos sanguíneos do cálcio, fósforo e magnésio durante a prenhez da jumenta.

As amostras foram colhidas de 15 jumentas, em diferentes periodos da gestação e no pós-parto.

$A$ dosagem do cálcio e magnésio foi efetuada pelo método de TODD e a do fósforo pela técnica de FISKE-SUBBAROW.

Para o cálcio verificou-se que na jumenta prenhe, a calcemia tende a se elevar com o progredir da gestação, atingindo teores maiores no pré-parto e assim se mantendo até o $3 .^{\circ}$ dia do puerpério, com uma significáncia estatística ao nível de $1 \%$.

Com relaçāo aos teores do fósforo inorgânico e do magnésio, nāo se obteve significância estatística dos resultados.

UNITERmos: Jumenta, prenhez*; Cálcio*; Fósforo*; Magnésio*; Sangue, níveis*.

\section{1 - INTRODUÇÃO E LITERATURA}

Em trabalho anterior foram analisados, OLIVEIRA19, entre outros fatores, os niveis sangüíneos do cálcio, do fósforo e magnésio durante a gestação da égua puro sangue inglês (p. s. i.). Verificou-se com relação ao cálcio, tendência para um estado de hipocalcemia no período final da gestação, o qual se acentuou na fase correspondente a 10 e 30 dias após o parto.

Para o fósforo, não se obteve diferença estatística significativa.

Para o magnésio, a análise da variância revelou que somente a média do período

* Professor Assistente Doutor.

* Professor Catedrático.

Departamento de Fisiologia e Farmacologia do Instituto de Ciências Biomédicas da U.S.P. 
OLIVEIRA, M. E. M.; TABARELLI NETO, J. F.; BIZUTTI, O. - Contribuição ao estudo dos teores séricos sangüíneos do cálcio, fósforo e magnésio durante a prenhez da jumenta, Equus asinus, Linnaeus, 1758. (Perissodactyla, Equidae). Rev. Fac. Med. vet. Zootec. Univ. S. Paulo, 12:169-84, 1975 .

compreendido entre 30-80 dias após a cobertura diferiu significativamente dos mais períodos.

Continuando a nos interessar pelo assunto, propusemo-nos a elaborar pesquisas similares no jumento (Equus asinus, Linnaeus, 1758). Em assim agindo procuramos esclarecer determinados aspectos fisiológicos apresentados pela espécie animal aludida, uma vez que são extremamente escassos os achados bibliográficos, principalmente no que tange à jumenta no decurso da prenhez, falha esta que leva muitos autores a utilizarem para o jumento determinados padrões fisiológicos específicos do cavalo, fato não válido, pois apesar de tratar-se de espécies mui próximas, são na realidade diferentes.

\section{2 - MATERIAL E MÉTODOS}

\subsection{Animais utilizados}

As jumentas utilizadas no presente trabalho eram em número de 15 , das quais, 13 eram da raça Italiana e 2 da Brasileira, com idade variando entre 5 a 12 anos e pertencentes à mesma fazenda, Estação Experimental de Zootecnia de Colina, localizada no município de Colina, Estado de São Paulo. Recebiam assistência veterinária permanente e foram consideradas clinicamente sadias. A todas era dado o mesmo tratamento quanto ao manejo, principalmente na parte de alimentação, confundindo-se assim, com o restante do rebanho.

\subsection{Coleta do material e tratamento sub- seqüente}

Por ocasião da coleta đo sangue, material utilizado no presente trabalho para a realização das diferentes técnicas abaixo descritas, os animais eram trazidos do pasto para os boxes, lugar onde eram sangrados imediatamente.

A coleta realizou-se sempre no período da manhã, por punção da veia jugular, com agulha $40 \times 20$. o sangue recolhido era deixado em repouso à temperatura ambiente (25 $35^{\circ} \mathrm{C}$ ), até coagulação e retração do coagulo. Em seguida, o soro era cuidadosamente retirado com auxílio de pipeta, colocado em frasco apropriado, e imediatamente congelado a $-10^{\circ} \mathrm{C}$, para ser transportado ao laboratório e estocado à temperatura de -15 a $-20^{\circ} \mathrm{C}$.

As jumentas foram sangradas pela primeira vez, antes da cobertura, a fim de se obter valores normais. Comprovada a gestação por palpação retal, sucediam-se novas coletas a intervalos que variavam entre 10 e 40 dias, até aproximadamente 15 dias antes da data provável do parto. A partir de então, as coletas foram feitas mais a amiúde, a cada 2-4 dias, até o parto. Ocorrido este, fizeram-se mais duas coletas, uma no dia seguinte e a última no 3. dia após o parto. Este proceder, controlando-se cada animal individualmente e processando-se a análise dos teores sangüíneos do $\mathrm{Ca}, \mathbf{P}$ e $\mathrm{Mg}$ antes de estabelecida a gestação, fez com que cada animal se tornasse testemunho de si próprio, afastando-se assim, as possíveis modificaçōes oriundas da diferença de raça e de idade.

\subsection{Dosagem do cálcio e magnésio}

Foi utilizado o método de TODD21.

\subsection{Dosagem do fósforo}

Foi utilizado o método de FISKE-SUBBAROW11, sendo que para as leituras, em lugar de colorímetro, empregou-se espectrofotômetro Coleman Jr., com comprimento de onda igual a $690 \mathrm{~nm}$.

\subsection{Análise estatística}

Antes de se proceder ao tratamento estatístico, foi necessário promover-se a uniformização dos resultados, mediante a divisão do tempo de gestação em periodos, já que a duração da prenhez dos animais utilizados na presente investigação apre- 
OLIVEIRA, M. E. M.; TABARELLI NETO, J. F.; BIZUTTI, O. - Contribuição ao estudo dos teores séricos sangüíneos do cálcio, fósforo e magnésio durante a prenhez da jumenta, Equus asinus, Linnaeus, 1758. (Perissodactyla, Equidae). Rev. Fac. Med. vet. Zootec. Univ. S. Paulo, 12:169-84, 1975 .

sentou notável variação, oscilando entre um mínimo de 350 e de um máximo de 417 dias. Assim, o tempo total da gestação de cada fêmea foi dividido em 9 períodos aproximadamente iguais. Cada período compreendeu, em médias, 42 dias, variando de 39 a 46, conforme a menor ou maior duração da prenhez. Os valores assinalados neste trabalho referem-se sempre ao fim de cada período, tendo sido consideradas, para cada animal, apenas as amostras colhidas até o limite de 7 dias antes do término de cada período. $O$ último período da gestação foi dividido, por sua vez, em 2 partes, a primeira correspondendo a 7-12 dias antes do parto, e a segunda a $0-6$.

Para a avaliação estatística dos resultados obtidos procedeu-se à análise da variância, conforme GOMES ${ }^{13}$.

Nos componentes em que foi anotada diferença significativa, procedeu-se também à análise da variância da regressão, pelo método dos polinômios ortogonais, conforme WINE ${ }^{23}$. Para manter a igualdade aproximada dos intervalos, tal análise foi efetuada exclusivamente com os valores de antes da cobertura e os compreendidos entre os períodos de I a IX (a) da gestação, não tendo sido incluído 0 período IX (b).

As parcelas perdidas foram preenchidas segundo SNEDECOR \& COCHRAN ${ }^{20}$ A cada parcela perdida correspondeu à yerda de 1 grau de liberdade na análise da variância.

\section{$3-$ R E S U T A D O}

\subsection{Variações nos niveis do cálcio total}

Os resultados referentes às variações nos níveis do cálcio total durante a prenhez encontram-se na tabela I e figura 1.

Os dados estatísticos relativos à análise da variância dos dados brutos, à análise da variância da regressão e seu desdobra- mento, apresentam-se nas tabelas II, III e IV, respectivamente. Analisando-as, verifica-se que a taxa do cálcio total tende a subir à medida que a gestação progride, mantendo-se ainda alta até o $3 .^{\circ}$ dia pós-parto (limite da observação). A análise estatística dos resultados revelou-se altamente significativa ao nível de $1 \%$.

A análise da variância da regressão, aplicada aos valores de antes da cobertura e aos correspondentes ao periodos de I a IX (a) da prenhez, revelou ser altamente significativo o termo linear, donde se conclui que os níveis de cálcio crescem com - avançar da gestação. O termo quadrático foi também significativo, 0 que sugere uma regressão curvilinea (parabólica) crescente.

\subsection{Variações nos níveis do fósforo inor- gânico}

Os resultados relativos aos teores de fósforo inorgânico, durante a prenhez, encontram-se na tabela $V$ e figura 2 e os correspondentes à análise da variância dos dados brutos, e à análise da variância da regressão, acham-se nas tabelas VI e VII, respectivamente.

Muito embora, a simples observação dos dados obtidos pareça mostrar decréscimo nos niveis de fósforo inorgânico com o progredir da gestação, tais resultados não foram estatisticamente significativos.

\subsection{Variações nos niveis do magnésio}

Os dados concernentes aos níveis do magnésio durante a gestação, encontram-se na tabela VIII e figura 3 . Os resultados da análise de variância da regressão estão contidos nas tabelas $\mathrm{IX}$ e $\mathrm{X}$, respectivamente.

As oscilações nos teores do magnésio foram mínimas durante o decurso da prenhez, não sendo revelada significância estatística, pela análise da variância dos resultados. 
OLIVEIRA, M. E. M.; TABARELLI NETO, J. F.; BIZUTTI, O. - Contribuição ao estudo dos teores séricos sangüíneos do cálcio, fósforo e magnésio durante a prenhez da jumenta, Equus asinus, Linnaeus, 1758. (Perissodactyla, Equidae). Rev. Fac. Med. vet. Zootec. Univ. S. Paulo, 12:169-84, 1975.

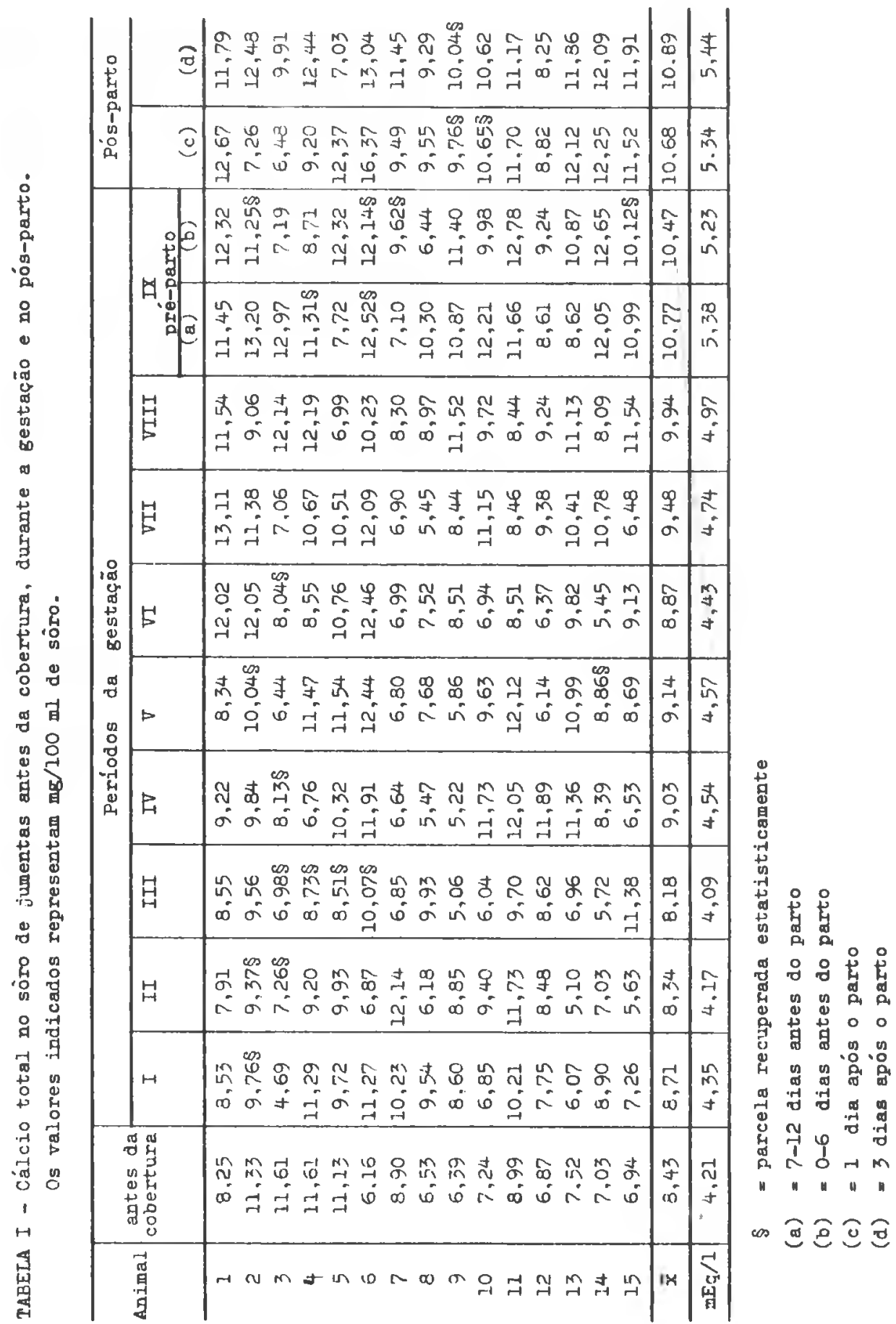


OLIVEIRA, M. E. M.; TABARELLI NETO, J. F.; BIZUTTI, O. - Contribuiçāo ao estudo dos teores séricos sangüineos do cálcio, fósforo e magnésio durante a prenhez da jumenta, Equus asinus, Linnaeus, 1758. (Perissodactyla, Equidae). Rev. Fac. Med. vet. Zootec. Univ. S. Paulo, 12:169-84, 1975.

T A B E L A I I

Cálcio total: análise da variância (totalidade dos dados).

\begin{tabular}{l|c|c|c|c}
\hline \multicolumn{1}{c|}{ VARIAÇAO } & G.L. & S.Q. & Q.M. & F \\
\hline \hline períodos & 12 & 174,8619 & 14,6718 & $3,6350 * *$ \\
animais & 14 & 183,7635 & 13,1260 & $3,2744 * *$ \\
residuo & 148 & 593,2882 & 4,0087 & \\
\hline \multirow{2}{*}{ TOTAL } & 174 & 951,9136 & & \\
\hline
\end{tabular}

(**) significativo ao nivel de $1 \%$.

T A B E L A I I I

Cálcio total: análise da variância dos dados aproveitados na análise da regressão. (Antes da cobertura até IX a).

\begin{tabular}{l|c|c|c|c}
\hline \multicolumn{1}{r|}{ VARIAÇAO } & G.L. & S.Q. & Q.M. & F \\
\hline \hline \multirow{2}{*}{ períodos } & 9 & 85,9718 & 9,5524 & $2,3586 *$ \\
animais & 14 & 140,9741 & 10,0696 & $2,4863 * *$ \\
resíduo & 113 & 457,6621 & 4,0501 & \\
\hline TOTAL & 136 & 684,6080 & & \\
\hline
\end{tabular}

(*) significativo ao nivel de $5 \%$.

(**) significativo ao nível de $1 \%$. 
OLIVEIRA, M. E. M.; TABARELLI NETO, J. F.; BIZUTTI, O. - Contribuiçāo ao estudo dos teores séricos sangüíneos do cálcio, fósforo e magnésio durante a prenhez da jumenta, Equus asinus, Linnaeus, 1758. (Perissodactyla, Equidae). Rev. Fac. Med. vet. Zootec. Univ. S. Paulo, $12: 169-84,1975$.

T A B E L A I V

Cálcio total: Desdobramento da análise da variância da regressão.

\begin{tabular}{|c|c|c|c|c|}
\hline VARIAÇĀO & G.L. & S.Q. & Q.M. & $\mathbf{F}$ \\
\hline Entre periodos & 9 & 85,9718 & 9,5524 & $3,5068 *$ \\
\hline Termo linear & 1. & 64,1798 & 64,1798 & $23,5609 * *$ \\
\hline Resíduo linear & 8 & 21,7920 & 2,7240 & \\
\hline Termo Quadrático & 1 & 13,4731 & 13,4731 & $11,3372 *$ \\
\hline Residuo corresp. & 7 & 8,3189 & 1,1884 & \\
\hline Termo Cúbico & 1. & 0,5684 & 0,5684 & 0,4400 \\
\hline Residuo corresp. & 6 & 7,7505 & 1,2918 & \\
\hline Termo Quártico & 1 & 0,5811 & 0,5811 & 0.4053 \\
\hline Resíduo corresp. & 5 & 7,1694 & 1,4339 & \\
\hline Termo Quíntico & 1 & 0,7583 & 0,7583 & 0,4731 \\
\hline Resíduo corresp. & 4 & 6,4111 & 1,6028 & \\
\hline
\end{tabular}

(*) significativo ao nivel de $5 \%$.

(*) significativo ao nível de $1 \%$. 
OLIVEIRA, M. E. M.; TABARELLI NETO, J. F.; BIZUTTI, O. — Contribuição ao estudo dos teores séricos sangüíneos do cálcio, fósforo e magnésio durante a prenhez da jumenta, Equus asinus, Linnaeus, 1758. (Perissodactyla, Equidae). Rev. Fac. Med. vet. Zootec. Univ. S. Paulo, 12:169-84, 1975.

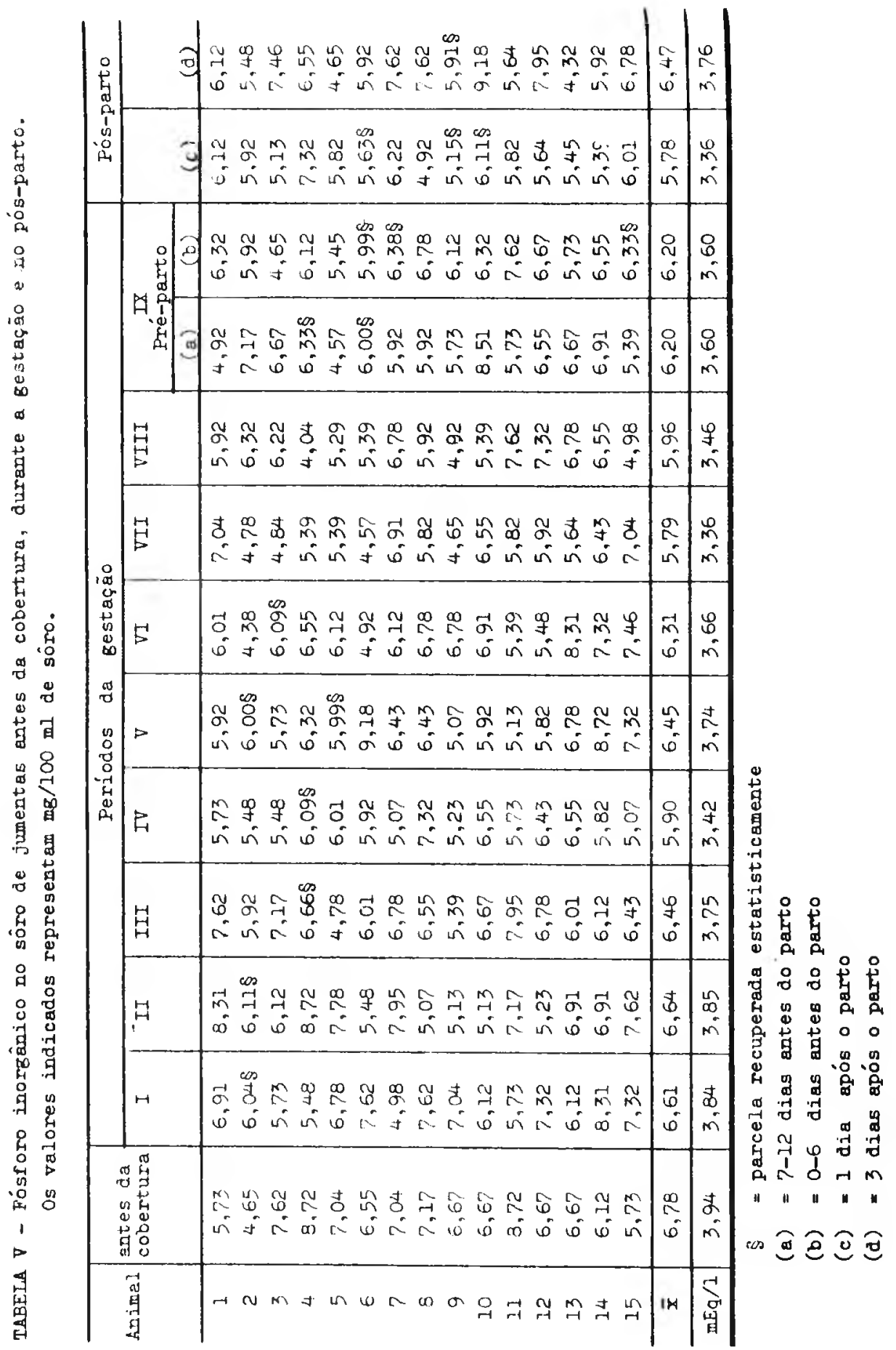


oliveira, M. E. M.; TABARELli NETO, J. F.; BIZUTTI, O. - Contribuição ao estudo dos teores séricos sangǘneos do cálcio, fósforo e magnésio durante a prenhez da jumenta, Equus asinus, Linnaeus, 1758. (Perissodactyla, Equidae). Rev. Fac. Med. vet. Zootec. Univ. S. Paulo, 12:169-84, 1975.

T A B E L A V I

Fósforo inorgânico: análise da variância (totalidade dos dados).

\begin{tabular}{l|c|c|c|c}
\hline \multicolumn{1}{c|}{ VARIAÇAO } & G.L. & S.Q. & Q.M. & F \\
\hline periodos & 12 & 20,2324 & 1,6860 & 1,6943 \\
animais & 14 & 19,5727 & 1,3681 & 0,9951 \\
residuo & 152 & 151,2529 & & 1,3748 \\
\hline TOTAL & 178 & 190,6380 & & \\
\hline
\end{tabular}

T A B E L A VII

Fósforo inorgânico: análise da variância dos dados aproveitados na análise da regressāo (antes da cobertura até IX a).

\begin{tabular}{l|c|c|c|c}
\hline \multicolumn{1}{c|}{ VARIACXO } & G.L. & S.Q. & Q.M. & F \\
\hline períodos & 9 & 15,6382 & 1,7376 & 1,6952 \\
animais & 14 & 15,7632 & 1,1259 & 1,0984 \\
resíduo & 117 & 119,9229 & 1,0250 & \\
\hline TOTAL & 140 & 151,3243 & & \\
\hline
\end{tabular}


OLIVEIRA, M. E. M.; TABARELLI NETO, J. F.; BIZUTTI, O. - Contribuição ao estudo dos teores séricos sangüíneos do cálcio, fósforo e magnésio durante a prenhez da jumenta, Equus asinus, Linnaeus, 1758. (Perissodactyla, Equidae). Rev. Fac. Med. vet. Zootec. Univ. S. Paulo, $12: 169-84,1975$.

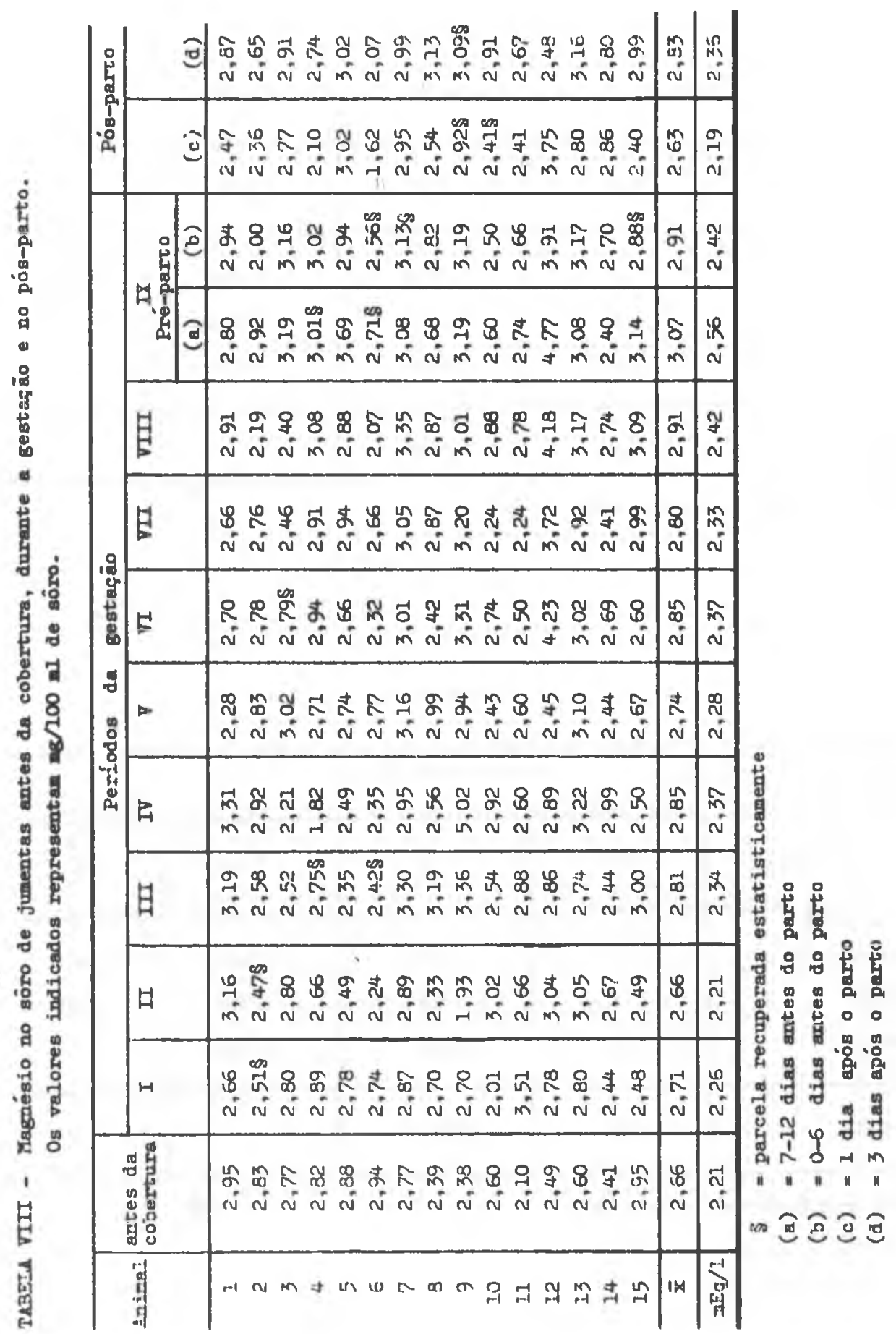


OLIVEIRA, M. E. M.; TABARELLI NETO, J. F.; BIZUTTI, O. - Contribuição a estudo dos teores séricos sangüíneos do ć́lcio, fósforo e magnésio durante a prenhez da jumenta, Equus asinus, Linnaeus, 1758. (Perissodactyla, Equidae). Rev. Fac. Med. vet. Zootec. Univ. S. Paulo, 12:169-84, 1975.

T A B E L A I X

Magnésio: análise da variância (totalidade dos dados).

\begin{tabular}{l|c|c|c|c}
\hline \multicolumn{1}{c|}{ VARIAÇAO } & G.L. & S.Q. & Q.M. & F \\
\hline & 12 & 2,7106 & 0,2259 & 1,4891 \\
periodos & 14 & 10,1411 & 0,7244 & $4,7752 * *$ \\
animais & 155 & 23,5179 & 0,1517 & \\
residuo & 181 & 36,3696 & & \\
\hline
\end{tabular}

(*) significativo ao nível de $1 \%$.

T A B E L A $\mathbf{X}$

Magnésio: análise da variância dos dados aproveitados na análise da regressão (antes da cobertura até IX a).

\begin{tabular}{l|c|c|c|c}
\hline \multicolumn{1}{c|}{ VARIAÇAO } & G.L. & S.Q. & Q.M. & F \\
\hline & 9 & 2,0673 & 0,2297 & 1,3879 \\
períodos & 14 & 7,0737 & 0,5053 & $3,0532 * 4$ \\
animais & 119 & 19,6939 & 0,1655 & \\
resíduo & 142 & 28,8349 & & \\
\hline
\end{tabular}

(*) significativo ao nivel de $1 \%$ 
OLIVEIRA, M. E. M.; TABARELLI NETO, J. F.; BIZUTTI, O. - Contribuiçāo ao estudo dos teores séricos sangüíneos do cálcio, fósforo e magnésio durante a prenhez da jumenta, Equus asinus, Linnaeus, 1758. (Perissodactyla, Equidae). Rev. Fac. Med. vet. Zootec. Univ. S. Paulo, 12:169-84, 1975 .

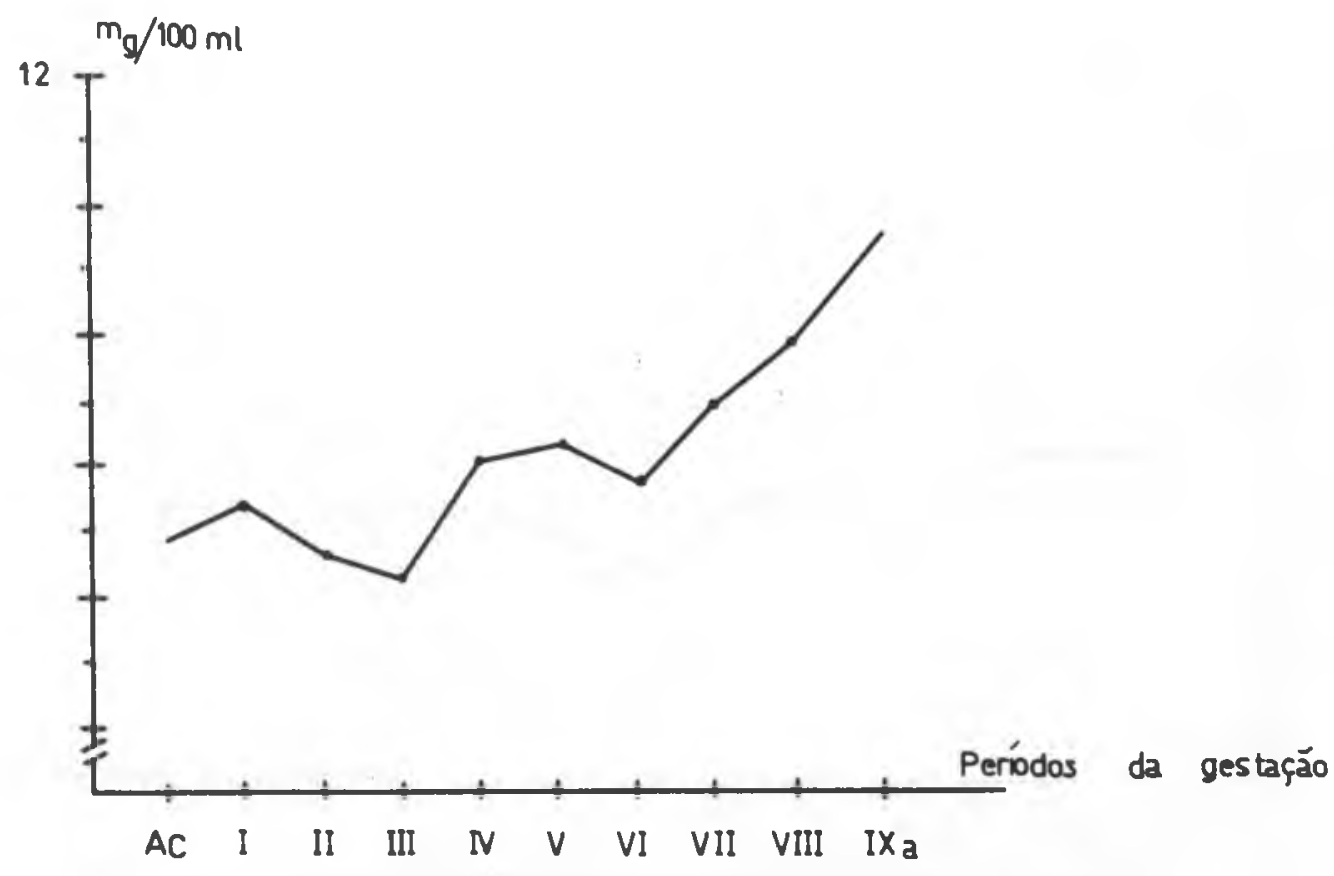

Figura 1. Cálcio total no soro de jumentas, antes da cobertura e durante a gestação.

Curva obtida com valores médios registrados na tabela I. - AC - antes da cobertura 
OLIVEIRA, M. E. M.; TABARELLI NETO, J. F.; BIZUTTI, o. - Contribuição ao estudo dos teores séricos sangüineos do cálcio, fósforo e magnésio durante a prenhez da jumenta, Equus asinus, Linnaeus, 1758. (Perissodactyla, Equidae). Rev. Fac. Med. vet. Zootec. Univ. S. Paulo, 12:169-84, 1975.

\section{$m_{g} / 100 \mathrm{ml}$}

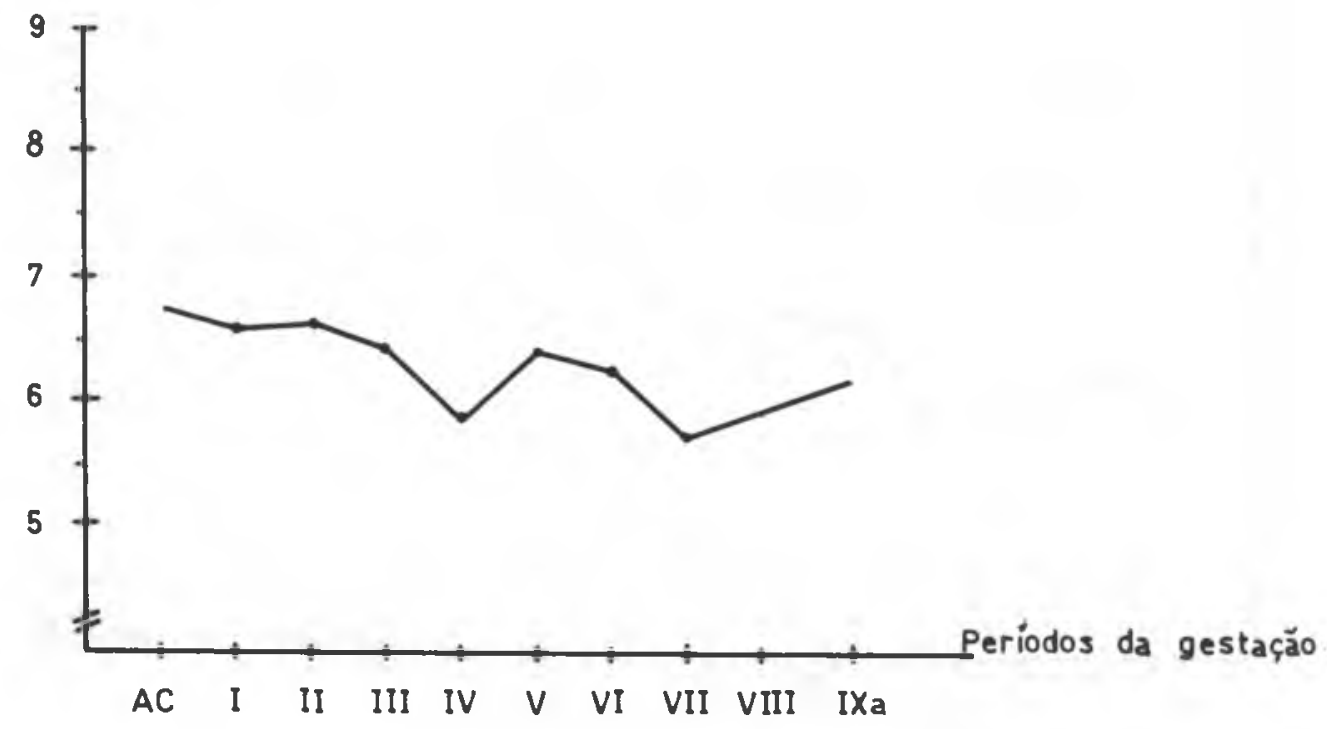

Figura 2. Fósforo inorgânico no soro de jumentas, antes da cobertura e durante a a gestação.

Curva obtida com valores médios registrados na tabela V. - AC - antes da cobertura. 
OLIVEIRA, M. E. M.; TABARELLI NETO, J. F.; BIZUTTI, O. - Contribuição ao estudo dos teores séricos sangüíneos do cálcio, fósforo e magnésio durante a prenhez da jumenta, Equus asinus, Linnaeus, 1758. (Perissodactyla, Equidae). Rev. Fac. Med. vet. Zootec. Univ. S. Paulo, 12:169-84, 1975.

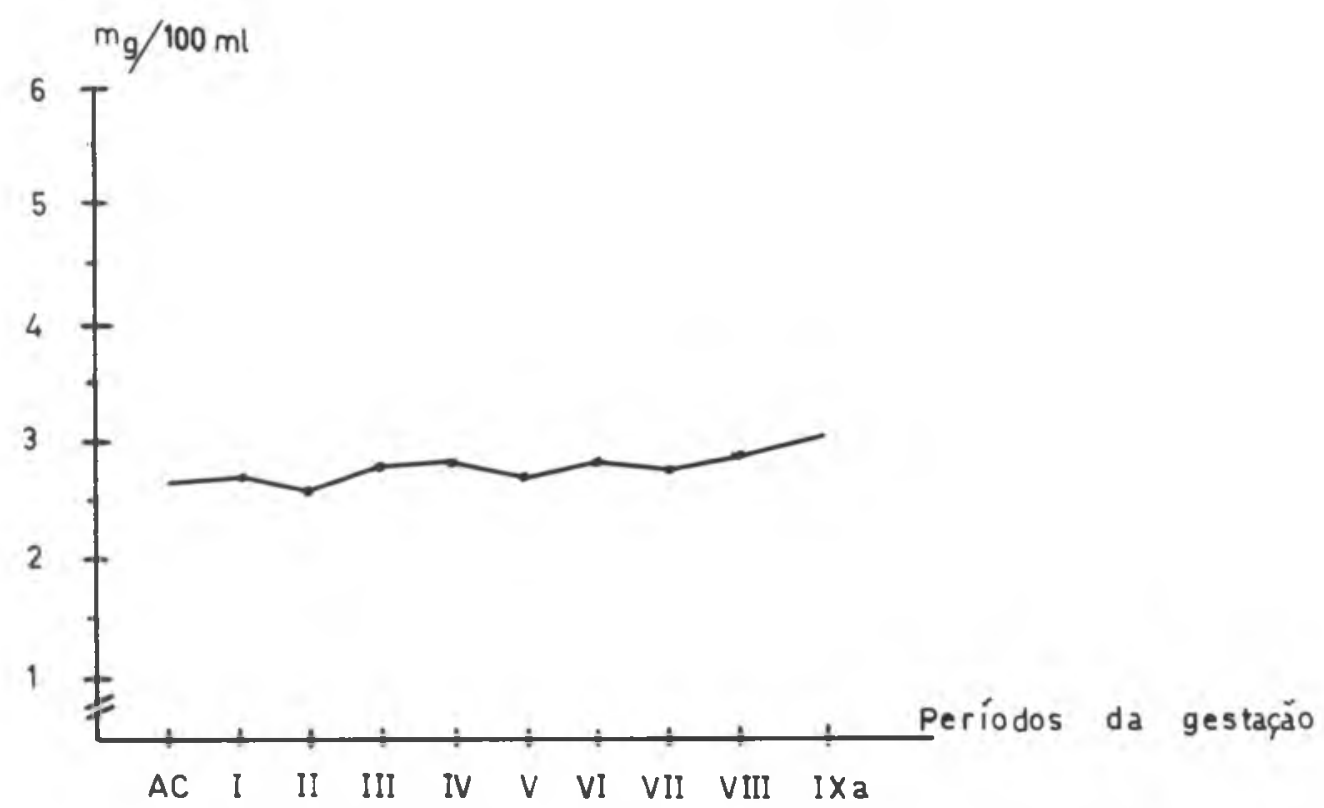

Figura 3. Magnésio no soro de jumentas, antes da cobertura e durante a gestação.

Curva obtida com valores médios registrados

na tabela VIII. - AC - antes da cobertura.

$$
4 \text { - D I S C U S S Ã } 0
$$

Entre os resultados obtidos salienta-se os referentes ao comportamento da curva calcêmica durante a prenhez da jumenta, já que o mesmo demonstrou ser totalmente oposto ao assinalado por autores outros em diferentes espécies animais incluindo-se a mulher.

Assim, enquanto que na jumenta a taxa de cálcio sanguíneo sobe concomitantemente com o progredir da prenhez, elevação esta altamente significativa à análise estatística, nas demais espécies domésticas e na mulher, segundo a maioria dos dados colhidos na literatura, a tendência da curva referida é para um declínio observável, sobretudo, nas fases finais da gestação.

OLIVEIRA19, com éguas p.s.i., registrou hipocalcemia nos períodos finais da gestação. Esta queda nos valores de cálcio sérico acentuou-se a partir do $280^{\circ} \mathrm{dia}$ da prenhez e assim se manteve até 30 dias após o parto (limite da observação), sendo que as médias assinaladas nestas ocasiōes foram, pela análise estatística, significativamente mais baixas do que os valores médios registrados nas outras fases da prenhez.

No referente à discordância por nós assinalada na jumenta prenhe, no que tange aos valores da calcemia no período pré-natal, julgamos de interesse assinalar o pensamento de alguns autores, com respeito aos fatores capazes de influírem sobre a mesma.

Assim, num conceito mais antigo e de acordo com BODANSKY \& DUFF2, o fato significativo do declínio nos níveis do cálcio sérico materno, durante os últimos meses da gestação, não pode ter como causa restrita a retirada do cálcio, pelo feto, a fim de atender ao seu desenvolvimento, pois, tal causa não explica, por exemplo, o 
OLIVEIRA, M. E. M.; TABARELLI NETO, J. F.; BIZUTTI, O. - Contribuiçāo ao estudo dos teores séricos sanguíneos do cálcio, fósforo e magnésio durante a prenhez da jumenta, Equus asinus, Linnaeus, 1758. (Perissodactyla, Equidae). Rev. Fac. Med. vet. Zootec. Univ. S. Paulo, 12:169-84, 1975.

porque da ocorrência do fenômeno mesmo em mulheres cujo histórico nutricional demonstra perfeito balanço mineral do alimento consumido durante a gestação.

Na mulher, umas das causas ligadas à hipocalcemia pré-natal poderia estar relacionada com a hipoproteinemia observável durante a gestação, muito embora, para alguns autores, tais como OBERST \& PLASS 18 e BODANSKY \& DUFF', tal correlação deixaria de existir nas fases finais da gestaçāo e do parto.

Todavia, GACEK ${ }^{12}$, estudando o comportamento das proteínas séricas durante a gestação da jumenta, cujas amostras de soro foram as mesmas utilizadas no presente trabalho, observou que durante a aludida condição e no pós-parto, as proteínas totais mantinham-se estáveis, não sendo estatisticamente significativa a diferença entre os vários períodos investigados da prenhez. Contudo, com relação à albumina, fração proteica que se liga ao cálcio, notou aumento linear na concentracão sangüínea com o progredir da gestação, atingindo teores mais elevados nas proximidades do parto e assim persistindo até o $30^{\circ} \mathrm{dia}$ do puerpério (limite da observação). Estatisticamente a diferença entre os períodos foi altamente significativa. Por outro lado, GUTMAN \& GUTMAN ${ }^{14}$, em sua equação de regressão, assinalam estar o cálcio sérico total mais relacionado com as concentrações da albumina e duas outras fraçōes de globulinas, do que propriamente com as proteínas totais.

No caso de ser válida para a jumenta prenhe, a correlação existente entre as concentraçōes séricas dó cálcio e da albumina, poder-se-ia aventar a hipótese de que um dos fatores responsáveis pela hipercalcemia pré-natal, observada nesta fêmea, estaria ligado à elevação na taxa sangüínea da albumina.

Contudo, o mecanismo responsável pela manutenção da calcemia foi revisto a partir de 1962 , ocasião em que COPP \& cols. 10 assinalaram a existência de um hormônio de efeito hipocalcêmico e hipofosfatêmico de origem paratireoideana e ao qual denominaram calcitonina. Posteriormente atribuiu-se sua origem às pequenas células parafoliculares da tireóide, passando-se denominá-lo por Tireocalcitonina (TC), HIRSCH \& cols.15 MacINTYRE \& cols.17. Todavia, a possibilidade da secreção de um composto similar pelas paratireóides não pode ser totalmente excluida, CARE \& cols. ${ }^{8}$. Como resultado da sua maior rapidez de ação e destruição, quando comparada ao hormônio paratireoideano, a TC agiria como um sistema de controle rápido da calcemia. Sugere-se que sua secreçāo seja regulada por um mecanismo de retro alimentação negativa operando por meio de uma maior concentração do cálcio plasmático.

Num conceito atual, portanto, a hipocalcemia pré-natal poderia estar associada a uma maior secreção de TC. Nesse sentido conviria assinalar o trabalho de CAPEN \& YONG $^{3}$ propondo que a febre vitular dos bovinos seja devida a uma liberação abrupta de TC e o de BARLET ${ }^{1}$ desencadeando em vacas, pela administração do hormônio referido, todos os sintomas da febre vitular, no momento em que a calcemia atingiu valores de $50 \mathrm{mg} / 1$ de plasma.

No que concerne a auto-regulação da calcemia, uma descarga de TC, como vimos, só poderia ser provocada por hipercalcemia e, assim, segundo JEAN-BLAIN 16 , a causa dessa maior liberacāo estaria ligada a fatores outros, uma vez que a febre vitular é precedida de uma reducão na calcemia, reducão esta já presente alguns dias antes do parto. Nesse sentido, o autor referido lembra as observaçōes de VAN SOEST \& BLOSSER 22 de acordo com as quais a hipocalcemia, bem como a hipofosfatemia, presentes nu momento do parto, estão ligadas à hiperglicemia. Esta última, por sua vez, estaria na dependência de uma maior produção de glucagon. Investigaçōes recentes têm atribuído a este último hormônio, a par de seu efeito hiperglicemiante, um outro hipocalcemiante. Semelhante efeito, indireto, estaria condicionado à capacidade do glucágon em ativar a síntese do 3'5' monofosfato de adenosina (AMP cíclico), a partir do ATP no interior das células parafoliculares da tireóide, o qual, por sua vez, estimularia a liberação do TC, CARE ${ }^{4}$ CARE \& cols. 5 , CARE \& BRUCE ${ }^{7}$. Assim, no período do pré-parto a tireóide seria solicitada a secretar o TC pela ativaçäo do sistema adenil ciclase, induzida pelo glucágon. Que a ativação deste último sistema, no interior das células parafoliculares da tireóide, é capaz de estimular a liberaçāo do TC nas condiçōes de hipercalcemia foi comprovado, no porco, por 
OLIVEIRA, M. E. M.; TABARELLI NETO, J. F.; BIZUTTI, O. - Contribuição ao estudo dos teores séricos sangüineos do cálcio, fósforo e magnésio durante a prenhez da jumenta, Equus asinus, Linnaeus, 1758. (Perissodactyla, Equidae). Rev. Fac. Med. vet. Zootec. Univ. S. Paulo, $12: 169-84,1975$.

CARE \& GITELMAN ${ }^{9}$, CARE \& cols. 5 os quais concluem que seus resultados não significam, necessariamente, que a estimulação do sistema adenil ciclase seja parte do mecanismo normal de liberação do TC em resposta à hipercalcemia.

Assim, se válido for o mecanismo aventado por JEAN-BLAIN ${ }^{16}$, fundamentado nas observações de VAN SOEST \& BLOSSER 22 e CARE \& GITELMAN 9 , na tentativa de explicar, em bovinos e outros animais, o mecanismo da hipocalcemia pré-natal, na jumenta, o estabelecimento, na mesma ocasião, de hipercalcemia seria motivada por mecanismo homeostático diferente e ainda por se elucidar.

No que diz respeito ao fósforo, os resultados assinalam tendência para hipofosfatemia à medida que a prenhez progride, simultânea à hipercalcemia observada, muito embora tal variação não tenha sido estatisticamente significativa.

Quanto ao magnésio, não foi observada variação digna de nota, não sendo estatisticamente significativas as pequenas diferenças registradas.

Durante a gestação da égua p.s.i., OLIVEIRA19 assinalou concentraçôes séricas mui próximas das encontradas na jumenta, sendo que somente a média compreendida entre 30-80 dias após a cobertura diferiu significativamente dos demais periodos investigados. Nesse ponto seria de interesse assinalar as observações de CARE \& cols. 6 acerca da capacidade do magnésio em estimular a secreção de TC quando perfundido através da tireóide, de porco, isolada "in situ", em concentrações de 4,4 - 12,7 $\mathrm{mEq} / 1$ e na presença de teor normal de cálcio no banho de perfusão. 0 efeito estimulante da hipermagnesemia foi usualmente menor que o causado por aumento equimolar no cálcio plasmático. Para os referidos autores as alterações nos teores sangüíneos do magnésio, provavelmente, não influem sobre a secreção de TC nas condições normais.

\section{C O N C L U S O E S}

Pelos resultados obtidos é lícito concluir:

1 - na jumenta prenhe, diferentemente do assinalado na égua puro sangue inglês de corrida, a calcemia tende a se elevar com o progredir da gestação, atingindo teores maiores no pré-parto e assim se mantendo até o 3.० dia do puerpério (limite da observação).

2 - Com relação aos teores do fósforo inorgânico e do magnésio no soro sangüíneo, não se obteve significância estatística dos resultados.

RFMV-A/16

Oliveira, M. E. M.; TabarellLi Neto, J. F.; BizutTi, O. - Blood serum levels of calcium phosphorus and magnesium during the pregnancy of the she ass, Equus asinus, L. 1758 (Perissodactyla, Equidae). Rev. Fac. Med. vet. Zootec. Univ. S. Paulo, 12:169-84, 1975.

SUMMARY: In this work the blood serum levels of calcium, inorganic phosphorus and magnesium during pregnancy of the she ass have been carried out.

Samples of blood have been collected from 15 she asses in differents periods of the pregnancy and in the post-partum.

Total calcium and magnesium were determined by the TODD method and the inorganic phosphorus by the FISKE-SUBBAROW method.

The levels of the total calcium were higher in the final periodo of pregnancy as well as in post-partum, with a statistical significance at the level of $1 \%$.

The results of the inorganic phosphorus and magnesium have not shown statistical significance differences among them.

UnITERMs: She ass, pregnancy*; Calcium*; Phosphorus*; Magnesium*; Blood serum levels*. 
OLIVEIRA, M. E. M.; TABARELLI NETO, J. F.; BIZUTTI, O. - Contribuição ao estudo dos teores séricos sangüíneos do cálcio, fósforo e magnésio durante a prenhez da jumenta, Equus asinus, Linnaeus, 1758. (Perissodactyla, Equidae). Rev. Fac. Med. vet. Zootec. Univ. S. Paulo, 12:169-84, 1975.

\section{REFERENCIAS BIBLIOGRAFICAS}

1. BARLET, J. P. - Induction expérimentale d'un syndrome analogue a la fièvre vitulaire par administration the thyrocalcitonine a des vaches en cours de lactation. C. R. Acad. Sci., Paris, $267: 2010-13,1968$.

2. BODANSKY, M. \& DUFF, V. B. - Regulation of the level of calcium in the serum pregnancy. J. Amer. med. Ass., $112: 223-29,1939$

3. CAPEN, C. C. \& YOUNG, D. M. - The ultrastructure of the parathyroid glands and thyroid parafollicular cells of cows with parturient paresis and hypocalcemia. Lab. Invest., 17:717-37, 1967.

4. CARE, A. D. - Endocrine control of calcium and magnesium metabolism in ruminants. Proc. Nutr. Soc., 28:183$89,1969$.

5. CARE, A. D.; BATES, R. F. L.; GITELMAN, H. J. - A possible role for the adenyl cyclase system in calcitonin release. J. Endocr., 48:1-15, 1970.

6. CARE, A. D.; BELL, N. H.; BATES, R. F. L. - The effects of hypermagnesaemia on calcitonin secretion "in vivo". J. Endocr., 51:381-86, 1971.

7. CARE, A. D. BRUCE, J. B. - Calcitonin - releasing substances: structure activity relationship. J. Endocr., 49: viii-ix, 1971.

8. CARE, A. D.; DUNCAN, T. WEBSTER, D. - Thyrocalcitonin and its role in calcium homeostasis. J. Endocr., 37: 155-67, 1967.

9. CARE, A. D. \& GITELMAN, H. J. The possible role of adenyl cyclase in thyrocalcitonin release. J. Endocr., 41: xxi-xxii, 1968.

10. COPP, D. H.; CAMERON, E. C.; CHENEY, B. A.; DAVIDSON, A. G. F.; HENZE, K. G. - Evidence for calcitonin. A new hormone from the parathyroid that lowers B blood calcium. Endocrinology, 70:638-49, 1962.

11. FISKE, C. H. \& SUBBAROW, Y. - The colorimetric determination of phosphorus. J. biol. Chem., 66:375-80, 1925.

12. GACEK, F. - Contribuiçāo do estudo das proteínas séricas sangüíneas de EQUUS ASINUS Linnaeus, 1758 (Perissodactyla, Equidae) - Pela eletroforese durante a gestaçāo e no pós-parto.
[Tese - Instituto de Ciências Biomédicas da Universidade de São Paulo].

13. GOMES, F. P. - Curso de estatistica experimental. Piracicaba, Escola Superior de Agricultura "Luiz de Queiroz", 1963.

14. GUTMAN, A. B. \& GUTMAN, E. B. Relation of serum calcium to serum albumin and globulins. J. clin. Invest., 16:903-19, 1937.

15. HIRSCH, P. F.; GAUTHIER, G. F.; MUNSON, P. L. - Thyroid hypocalcemic principle and recurrent laryngeal nerve injury as factors affecting the response to parathyroidectomy in rats. Endocrinology, 73:244-52, 1963.

16. JEAN-BLAIN, M. - Etat actual des connaissances sur les metabolismes du calcium et du phosphore chez les animaux domèstiques. Cah. Med. Vet., $40: 100-29,1971$.

17. MAcINTYRE, I.; FOSTER, G. V.; KUMAR, M. A. - The thyroid origem of calcitonina apud CARE, A. D.; DUNCAN, T.; WEBSTER, $\mathrm{D}^{8}$, p. 156 .

18. OBERST, W. F. \& PLASS, E. D. - The variations in serum calcium, protein, and inorganic phosphorus in early and late pregnancy, during parturition and the puerperium, and in non pregnant women. J. clin. Invest., 11:123-27, 1932.

19. OLIVEIRA, M. E. M. - Niveis sangüíneos do cálcio, fósforo, magnésio e correlaçāo entre calcemia e fosfatase alcalina, durante a prenhez da égua puro sangue inglês (p.s.i.). S. Paulo, 1970, [Tese - Faculdade de Medicina Veterinária e Zootecnia da Universidade de São Paulo].

20. SNEDECOR, G. W. \& COCHRAN, W. G. - Statistical methods. 6th ed. Ames, Iowa State College Press, 1967.

21. TODD, J. R. - The determination of calcium and magnesium in blood serum by direct titration. Brit. vet. J. 115:86-9, 1959.

22. VAN SOEST \& BLOSSER - apud JEANBLAIN, $M^{16}$ p. 128.

23. WINE, R. L. - Statistics for scientists and engineers. New Jersey, PrenticeHall, Englewoods Cliffs, 1964.

Recebido para publicação em 26-8-75

Aprovado para publicação em 17-9-75 